Memorias del VIII Encuentro Nacional de Experiencias en Enseñanza de la Biología y la

Educación Ambiental. III Congreso Nacional de Investigación en Enseñanza de la Biología.

\title{
Ideas Previas Acerca de "Evolución y Su Relación con la Genética" en Estudiantes de Grado Noveno del Colegio Nicolás Esquerra
}

Previous Ideas Stablished By Students of Ninth Grade of Nicolas Esguerra National High School About "The Evolution Concept And The Support Of Genetics" To Their Explanations

\author{
Sergio Alejandro Peláez Plazas, Lilia Alejandra Perlaza Berrio \\ seapelaezp@correo.udistrital.edu.co, laperlazab@correo.udistrital.edu.co
}

\section{Resumen.}

Como primera experiencia didáctica, en este trabajo se muestran las ideas previas que construyen 10 estudiantes de noveno grado del colegio Nacional Nicolás Esguerra acerca del proceso de evolución, las cuales se encuentran relacionadas con algunos conceptos que aborda la genética. Los datos fueron recogidos por medio de una encuesta de pregunta abierta y un dibujo en base al método cualitativo, con el fin de conocer la comprensión que los estudiantes tienen acerca de la evolución y los conceptos mencionados en sus explicaciones, entre los cuales se encontraron: adaptación, ADN y código genético, relacionando en estos el tiempo como factor de cambio. Estas ideas se organizaron en tres categorías (Comprensión de Procesos evolutivos basados en variabilidad y selección natural e Ideas relacionadas al catastrofismo como factor promotor de especiación). Entre estas, la mayoría de los alumnos hace alusión a cambios en el ciclo de vida y desarrollo, y no como un proceso a nivel histórico y constante en las poblaciones. En cuanto a la comprensión del ADN, el gen y su relación con las especies, no hay claridad con respecto a la expresión de caracteres desde la información que se expresa en las proteínas. Por consiguiente, se infiere que las ideas encontradas están poco articuladas ya que ellos no las logran conectar de forma apropiada en sus respuestas.

Palabras claves: Herencia, Adaptación, Código genético, ADN.

\section{Abstract.}

As the first learning experience, in this work the previous ideas about the process of evolution built by 10 students from the National High school Nicolas Esguerra are shown, which are related to some concepts involved by genetics, due to this was the topic seen during the first academic term. Data were collected through a survey of open question and a drawing based in the interpretative method in order to know the students' understanding about Evolution and concepts mentioned in their explanation, like: Adaptation, DNA, Genetics code, making relations with the time as change 
Memorias del VIII Encuentro Nacional de Experiencias en Enseñanza de la Biología y la Educación Ambiental. III Congreso Nacional de Investigación en Enseñanza de la Biología.

factor. This ideas were categorized (Comprehension of evolutionary process based in variability and natural selection and ideas related to catastrophism as change promoter factor). However, most of them alluded to changes in the life cycle and development and not as a historical and constant process amongst populations. As for the understanding of DNA, the gene and its relationship with every species, there is not clarity regarding the character expression and the information expressed in proteins. Therefore it is inferred that the ideas are quit loose that fail to be connected properly.

Key words: Inheritance, Adaptation, Genetic code, DNA.

\section{Introducción.}

Las ideas previas han sido denominadas de diferentes formas según las teorías y la connotación del enfoque propuesto por diversos autores quienes hacen énfasis en el papel especifico que estas juegan en el aprendizaje de diversos contenidos de Ciencias Naturales (Rayas J., s.f).

Se considera que las ideas previas son construcciones que el estudiante elabora para dar respuesta a su necesidad de interpretar fenómenos naturales o conceptos científicos, y para proponer explicaciones, descripciones o predicciones (Bello, 2004). Estas ideas surgen a partir de las experiencias cotidianas, las actividades físicas, las conversaciones con otras personas, y de la información de los medios de comunicación, entre otros factores (Rayas J., s.f). Por lo cual, Giordan (1989) manifiesta que "para dar una enseñanza que tenga un mínimo de éxito, será necesario explorar y conocer estas concepciones (ideas previas) tal como funcionan realmente (y no como se supone que lo hacen) e interferir con ellas" (p.4).

Por tanto, en el presente artículo se pretende señalar las ideas previas que 10 estudiantes de noveno grado del colegio Nacional Nicolás Esguerra Jornada de la tarde toman acerca del concepto de evolución, las cuales surgen cuando el estudiante construye en base a su experiencia y el nuevo conocimiento e interactúa con los esquemas ya existentes (Cubero, 1997). Generalmente, se espera que el nuevo conocimiento se construya partiendo de las ideas previas del alumno, sin embargo, lo que ocurre es que este realiza una síntesis entre lo que él conoce y lo que cuenta el maestro, aprende algunos conocimientos superficialmente, o, simplemente con el paso del tiempo va olvidando lo trabajado en clase y sigue actuando de acuerdo con lo que ya sabía (Cubero, 1997).

Para hacer mención de las ideas previas que tienen los estudiantes de grado noveno se hace necesario señalar que la evolución biológica es entendida como la derivación de las especies de organismos vivientes, de otras ya existentes, a través de 
Bio -grafía. Escritos sobre la Biología y su Enseñanza. ISSN 2027-1034

Edición Extraordinaria. p.p.1721-1730

Memorias del VIII Encuentro Nacional de Experiencias en Enseñanza de la Biología y la Educación Ambiental. III Congreso Nacional de Investigación en Enseñanza de la Biología.

un proceso de cambio más o menos gradual y continuo (Molina, 2013). Con respecto a esto, Fernández y Sanjosé (2007) afirman que la mayoría de los estudiantes están dispuestos a aceptar el concepto de evolución como fenómeno, evitando teorías fijistas y admitiendo que los seres vivos del pasado eran diferentes a los actuales y que hay relación entre ellos. Sin embargo a la hora de explicar este fenómeno es cuando surgen generalmente las ideas previas (p.125). Bartov $(1978,1981)$ propone que las ideas previas hacen referencia a connotaciones teleológicas, es decir, que detectan propósitos como causas. Esta idea se encuentra arraigada, de tal forma que permanece incluso en aquellos estudiantes que han estudiado biología evolutiva desde edades muy tempranas (Bernedo, 2011).

Desde el punto de vista de diferentes autores se ha encontrado que existe una dificultad en los estudiantes a la hora de tratar los contenidos sobre la herencia biológica, los caracteres hereditarios y su transmisión. Para lo cual existirían varias posibles causas para este problema, entre las cuales: las ideas previas de los estudiantes, algunas de ellas fruto del lenguaje común, estarían fuertemente arraigadas y actuarían como obstáculos que dificultan la comprensión de la genética mendeliana bloqueando la comprensión de los mecanismos de la herencia; se darían confusiones terminológicas en conceptos genéticos (Caballero, 2008).

Por otra parte, la dificultad en la comprensión de los conceptos fundamentales en la evolución se basa en los mecanismos evolutivos apoyados en variabilidad y selección natural, así como señalan Fernández y Sanjosé (2007): "los alumnos de niveles de primaria y primer ciclo de secundaria no conciben la existencia de variabilidad intraespecífica. No existe para ellos relación entre variabilidad, selección y adaptación" (p.140). Baumgarther \& Dunkan (2009) mencionan que a los estudiantes les cuesta comprender como un individuo representa la variabilidad de toda una población, y que esa variabilidad es necesaria para el cambio evolutivo, tampoco distinguen la diferencia entre individuo y especie cuando describen la selección natural (p.218).

\section{Metodos.}

Para la exploracion de las ideas previas de los 10 estudiantes de grado noveno, con edades entre los 13 y 16 años, se emplearon cuestionarios semi estructurados basados en preguntas abiertas y un dibujo explicativo como lo propone Rosario Cubero (1997), los cuales fueron diseñados y discutidos en base al método de investigación cualitativo desde la posición de Denzin \& Lincoln (1994) quienes lo definen como una investigación multimetódica, naturalista e interpretativa. Es decir, los investigadores cualitativos indagan en situaciones naturales, intentando dar sentido o interpretar los fenómenos en los términos del significado que las personas les otorgan. Además, en 
Memorias del VIII Encuentro Nacional de Experiencias en Enseñanza de la Biología y la Educación Ambiental. III Congreso Nacional de Investigación en Enseñanza de la Biología.

los cuestionarios elaborados se evitó emplear términos que encaminen a los alumnos a una respuesta que no sea propiamente de ellos, propuesta sugerida por Jiménez (1991) (Tabla 1). Dichos instrumentos se aplicaron en el aula de clase a finales del primer periodo academico, momento en el cual se estaba dando por terminada la enseñanza del concepto de Genetica, para dar paso a la evolucion en el segundo periodo académico.

Por otra parte, el análisis de los resultados se hizo tomando referentes categoricos propuestos por diversos autores, como: Comprensión de Procesos evolutivos basados en variabilidad y selección natural (Fernández y Sanjosé, 2007), e Ideas relacionadas al catastrofismo como factor promotor de especiación (Bernedo, 2011).

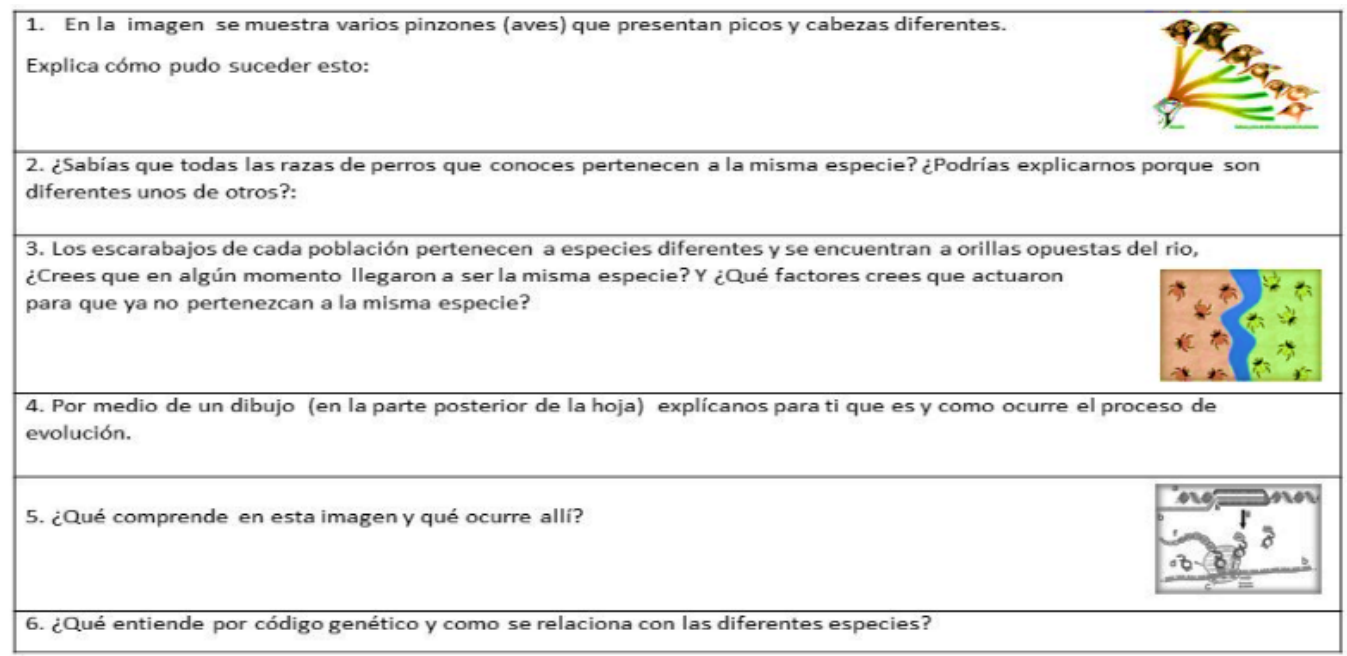

Tabla 1: preguntas propuestas en los intrumentos que se aplicaron a los estudiante

\section{Resultados y Discusión.}

Se puede decir que las ideas previas que tienen los estudiantes de grado noveno respecto al concepto de evolución están relacionas conceptualmente a la genética, pero relacionada con otros factores, los cuales se abarcaron en dos categorías:

\section{Comprensión de Procesos evolutivos basados en variabilidad y selección natural}

El tiempo es mencionado por algunos de los estudiantes como un factor que influye en los procesos de adaptación y especiación: "Si fueron la misma especie pero en cuanto a tiempo y evolución cambiaron y parecían distinta especie" (Daniel, 15 años), "porque a través del tiempo sus cuerpos evolucionan adaptándose a las circunstancias que viven" (Camilo, 16 años), "pudieron llegar a serlo (los escarabajos) pero debido al 
Memorias del VIII Encuentro Nacional de Experiencias en Enseñanza de la Biología y la Educación Ambiental. III Congreso Nacional de Investigación en Enseñanza de la Biología.

cambio de habitad se adaptaron" (Santiago, 13 años), "porque a nivel de genética y tiempo todo evoluciona, sea para mejorar o empeorar" (Juan, 15 años), "con el paso del tiempo van mejorando (los perros) por decirlo así y cambian de forma" (Steven, 15 años) y "Porque el primer perro tenia genes de varias formas, aunque a través del tiempo esos genes fueron reflejándose en algunos y otros en otros" (Matias, 15 años). En estas respuestas citadas, ellos nombran el tiempo como conjunto de cambios sucesivos, sin aclarar su perspectiva del mismo. Es por ello, que nos remitimos a las representaciones graficas realizadas por los estudiantes, donde se evidencia que no relacionan sus explicaciones dadas en las preguntas puntuales con lo plasmado por ellos; ya que a pesar de que mencionan adaptación y cambio en el código genético, algunos ven esta relación desde periodos cortos de tiempo en los que se da el desarrollo y el crecimiento y no como procesos cronológicos prolongados en los que sucede la evolución Figura 1. Además, no logran relacionar los procesos de adaptación y variabilidad como lo mencionan Baumgarther \& Dunkan (2009), ya que intentan explicar los procesos de una forma independiente, sin integrar varios factores, ya sean cambios físicos, ambientales o cambios en los genes.

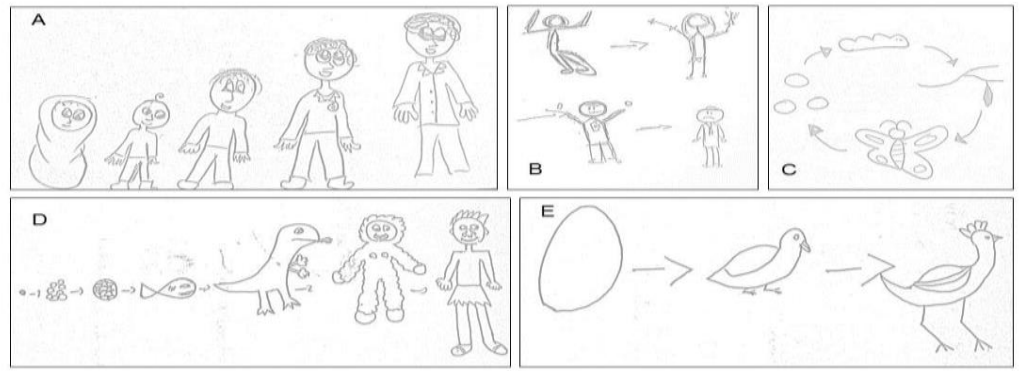

primitivo a Indígena que llega a ser estudiante del colegio Nicolás Esguerra y por último profesional) B; el desarrollo también fue representado en la eclosión y crecimiento de un ave o la metamorfosis de una mariposa $\boldsymbol{C}$ y $\boldsymbol{E} ;$; algunos también vieron este proceso como la evolución de organismos sencillos hasta unos más complejos $\boldsymbol{D}$.

Por otro lado algunos de los estudiantes hacen mención a factores etológicos como las decisiones que toman los organismos para distinguirse de otros: "Con la evolución, los animales y los seres vivos han cambiado mucho en sus diferentes formas de ser (Andrés, 13 años)" $y$ "es el código genético donde van los genes de los seres vivos, por eso es que las especies de los animales no varían sino en su forma de pensar" 
Memorias del VIII Encuentro Nacional de Experiencias en Enseñanza de la Biología y la Educación Ambiental. III Congreso Nacional de Investigación en Enseñanza de la Biología.

(Steven, 15 años), con esto se infiere que ellos creen que la evolución se da en términos de decisión en cuanto a actuar de forma diferente a sus congéneres $y$, también, debido a que ven el ADN como una molécula totalmente diferente refiriéndose a los individuos de la misma población: "son diferentes porque llevan diferente $A D N$ pero son todos la misma especie" (Juan, 15 años), lo que puede diferir a lo encontrado por Fernández y Sanjosé (2007) quienes afirman que los estudiantes no conciben la existencia de variabilidad intraespecífica. Empero, se encontraron ideas opuestas que apoyan lo propuesto por los autores: "todos tiene el mismo tipo de ADN, pero en el grupo de escarabajos cada uno salió de diferente especie"

En cuanto a herencia, los alumnos manifiestan que los genes se expresan de una generación a otra, de la siguiente manera: "El código genético es donde se llevan los genes de generación tras generación, tanto en animales como humanos" (Matías, 15 años), "es una transformación que se da respecto a los genes hereditarios, se relacionan en que todas las especies vivas tiene código genético" (Sebastián, 16 años) y "por diferentes estructuras genéticas que se le han adaptado a esta especie y por mezclar diferentes aspectos genéticos hereditarios" (Kevin, 14 años). Según Caballero (2008) los estudiantes tienen dificultades a la hora de tratar la herencia biológica y darle explicación, por lo cual, mencionan el concepto, más no lo desarrollan.

\section{Catastrofismo como factor promotor de especiación.}

Predinaci (1987) (como se cita en Bernedo, 2011, p.7) afirma que el catastrofismo es una respuesta muy utilizada por los estudiantes para dar explicación a la evolución, esto se encontró en una de las respuestas que uno de los estudiantes dio acerca de la especiación de los escarabajos: "la misma especie, pero por una catástrofe o radioactividad se separaron (los escarabajos)" (Camilo, 16 años).

Además es evidente que los estudiantes mencionan la genética como un factor cambiante y distintivo en cada especie, pero muchos no tienen claro los conceptos que escriben y los procesos que se llevan a cabo en la expresión del ADN en proteínas y el genoma que difiere en cada especie, ya que en el gráfico de síntesis de proteínas solo cuatro estudiantes hacen mención a ello, donde no es claro si entienden el proceso, debido a que ellos se limitaron a dar una respuesta caprichosa como lo dice Cuberos (1997).

\section{Conclusiones.}

Entre las ideas previas de los estudiantes de grado noveno, se identifica, el cambio biológico asociado al tiempo, relacionado por ellos como un periodo cronológico corto 
Memorias del VIII Encuentro Nacional de Experiencias en Enseñanza de la Biología y la Educación Ambiental. III Congreso Nacional de Investigación en Enseñanza de la Biología.

en el que sucede el ciclo de vida y desarrollo de los individuos y no, como la derivación de las especies de organismos vivientes de otras ya existentes, a través de un proceso de cambio gradual y continuo.

En cuanto a la comprensión que tienen los estudiantes acerca de procesos evolutivos basados en variabilidad y selección natural: La mayoría de las ideas encontradas en los estudiantes hacen relación a cambios en los genes, los cuales determinan si una especie se adapta o no, si dichos cambios son favorables y heredables a las futuras generaciones. En estos cambios, algunos de ellos integran factores etológicos como la decisión que toman los organismos de transferir los genes a las siguientes generaciones. Entre sus ideas, ellos se apoyan en conceptos de genética disociando el ADN del código genético, pero integrándolos en sus explicaciones.

En lo que respecta a catastrofismo como factor promotor de especiación, Algunos de los estudiantes dan explicación a procesos de especiación por medio de fenómenos naturales que propician la separación de las poblaciones hacia diferentes ambientes. La relación conceptual que hacen los estudiantes de grado noveno acerca de la genética como un factor promotor de evolución se encuentra poco articulada, ya que ellos no la logran conectar de forma apropiada con los procesos evolutivos, generando dificultad en la comprensión de conceptos fundamentales en la evolución debido a que se basan en el uso de conceptos genéticos como apoyo para dar explicación a esta teoría, asimilándolos tácitamente para dar soporte a sus ideas previas, aun sin tener una claridad sobre los mismos.

\section{Bibliografía.}

Baumgartner, E., y Duncan K. (2009). Evolution of Student's Ideas About Natural Selection Through A Constructivist Framework. The American Biology Teacher.71 (4), 218.

Bello, S. (2004). Ideas Previas Y Cambio Conceptual. Educación Química 15[3], 210. Bernedo, V. (2011). Concepciones alternativas sobre evolucion en $1^{\circ}$ de ESO. IES Xoan Montes (Lugo). 10-11.

Caballero, M. (2008). Algunas Ideas Del Alumno De Secundaria Sobre Conceptos Básicos De Genética. Enseñanza De Las Ciencias, 26(2), 227-244. Cubero, R. (1997). Cómo Trabajar Con La Ideas Previas De Los Estudiantes, 4a . Ed.,.1, Sevilla, Diada Serie Practica (Colección Investigación Y Enseñanza).

Denzin, N. K., y Lincoln,Y. S. (1994). «Introduction: entering the field of qualitative research», en N. K. Denzin e Y. S. Lincoln (eds.), Handbook of Qualitative Research. Thousand Oaks, California, Sage. 
Bio -grafía. Escritos sobre la Biología y su Enseñanza. ISSN 2027-1034

Edición Extraordinaria. p.p.1721-1730

Memorias del VIII Encuentro Nacional de Experiencias en Enseñanza de la Biología y la Educación Ambiental. III Congreso Nacional de Investigación en Enseñanza de la Biología.

Duit, R. (Sin Fecha). «Learning De Energy Concept In School: Empirical Resulys From The Phillippines And West Germany» En: Physics Education.19 Germany 1984. Pp. 5966.

Fernández, J.J. y Sanjosé, V. (2007). Permanencia de ideas alternativas sobre Evolución de las Especies en la población culta no especializada. Didáctica de las ciencias experimentales y sociales. (21), 127-149.

Giordan, A. 1989. De Las Concepciones De Los Alumnos A Un Modelo De Aprendizaje Alostelico. Investigacion En La Escuela, 8, 4.

Giordan, A. La Enseñanza De Las Ciencias. Siglo XXI. Madrid España.1982. Vid.

Helm, H. 2000.Misconceptions About Physical Concepts Among .South African Pupils Studyng Phisical Science. South African Journal Of Science. [74]. 285 - 290.

Jiménez, A. (1991). Cambiando las ideas sobre el cambio biológico. Enseñanza De Las Ciencias, 1991,9 (3), 248-256.

Mcdermot, M.1984. Research On Conceptual Understanding In Mechanics En: Physics Today (July). Egland.. Pp. 24 -32

Molina, M. (2013). Teoría General de la Evolución condicionada a la Vida. Molwick. 4 ed.33-37

Novak, J. (1983). "Overview Of The Seminar» Proceedings Of The International Seminar: Misconceptions In Science And Mathematics, Ithaca, Commell University Press. USA.

Rayas, J., (Sin Fecha), El Reconocimiento De Las Ideas Previas Como Condición Necesaria Para Mejorar Las Posibilidades De Los Alumnos En Los Procesos Educativos En Ciencias Naturales.

Rosalind Driver.(1978). «Pupils And Paradigms: A Review Of Literatura Related To Concepts Development In Adolescent Science Students» Studies In Science Education. 5,. Pp. 61-84.

Viennot. (1979). Spontaneous reasoning in elementary dynamics. Eur, J. Sci. Educ. 205-206 